\title{
Archipel
}

ARCHIPEL Études interdisciplinaires sur le monde insulindien

$97 \mid 2019$

Varia

\section{7th Borobudur Writers and Cultural Festival 2018, Yogyakarta-Borobudur, 22-24 November 2018}

\section{Henri Chambert-Loir}

\section{(2) OpenEdition}

1 Journals

\section{Édition électronique}

URL : https://journals.openedition.org/archipel/999

DOI : 10.4000/archipel.999

ISSN : 2104-3655

Éditeur

Association Archipel

\section{Édition imprimée}

Date de publication : 11 juin 2019

Pagination : 8-12

ISBN : 978-2-910513-81-8

ISSN : 0044-8613

\section{Référence électronique}

Henri Chambert-Loir, «7th Borobudur Writers and Cultural Festival 2018, Yogyakarta-Borobudur, 22-24 November 2018 », Archipel [En ligne], 97 | 2019, mis en ligne le 11 juin 2019, consulté le 20 septembre 2021. URL : http://journals.openedition.org/archipel/999 ; DOI : https://doi.org/10.4000/archipel.999 


\section{7th Borobudur Writers and Cultural Festival 2018, Yogyakarta-Borobudur, 22-24 November 2018}

Les festivals artistiques et littéraires se sont multipliés en Indonésie ces dernières années. Les trois les plus connus sont le Ubud Writers and Readers Festival (depuis 2004), le Makassar International Writers Festival (depuis 2011) et le Borobudur Writers and Cultural Festival (BWCF, depuis 2012).

Le BWCF a été créé par Romo Mudji Sutrisno (prêtre jésuite, professeur de philosophie et essayiste), Seno Joko Suyono (journaliste, enseignant et romancier) et Imam Muhtarom (enseignant et écrivain), dans le but de permettre la rencontre d'écrivains, d'intellectuels et d'acteurs de la scène culturelle et religieuse, et de célébrer l'originalité et la richesse de l'Indonésie dans les domaines de la littérature, des arts et des religions. L'Indonésie ou plus généralement l'espace nousantarien, est le sujet exclusif. L'idée fondatrice n'est pas de distraire ou d'offrir des prestations intellectuelles et artistiques admirables, mais de donner à réfléchir. Un thème inspire les activités de chaque festival : de 2012 à 2017, ces thèmes ont été successivement : Romans de cape et d'épée (silat) et histoire ; Les épices et la mer; Ratu Adil : pouvoir et révolte ; Montagnes et mythologie ; Serat Centhini ; Gandavyuha et la quête religieuse.

Le thème du septième festival était : Diary \& Traveling, Setelah 1300 Tahun Buku Harian I-Tsing, Merayakan Kisah-Kisah Lawatan Tentang Nusantara ( « Journaux et voyages, 1300 ans après le rapport de I Tsing, célébrer les récits de voyage sur l'Insulinde »).

Le festival s'est tenu en deux actes distincts. Le premier était une soirée d'inauguration organisée dans les règles usuelles des grands congrès, dans un grand hôtel de Yogyakarta ; le deuxième, moins conventionnel, s'étalait sur 
deux jours, de 5 heures du matin à 11 heures du soir, dans le parc touristique du Borobudur.

La séance d'inauguration, le 22 novembre, à l'Hotel Grand Ina Malioboro, fut ouverte par un discours de Mudji Sutrisno SJ et une adresse de Toeti Herati. Le Père Mudji Sutrisno (« Romo Mudji »), qui a fait le pèlerinage de Santiniketan (l'école fondée par Tagore, au Bengale, en 1901), conçoit le thème du colloque comme une lecture introspective des témoignages étrangers, dans lesquels on peut voir la grandeur passée de l'Archipel.

Puis eut lieu le lancement de neuf livres en rapport avec le thème du festival (voyages, témoignages, migrations et contacts). Neuf présentateurs : Salim Lee (le texte de I Tsing: Yi Jing, Kiriman Catatan Praktik Buddhadharma dari Lautan Selatan, traduit de la version anglaise de J. Takakusu, Jakarta : Direktorat Sejarah dan Nilai Budaya Ditjen Kebudayaan, Kementerian Pendidikan dan Kebudayaan, 2014, xiii-420 p., ouvrage non commercialisé, mais lisible en ligne sur $<\mathrm{https}$ ://fr.slideshare.net/AgustinAyunk/kirimancatatan-praktik-buddhadharma-dari-lautan-selatan>) ; Tan Ta Sen (Cheng Ho Penyebar Islam dari China ke Nusantara, Kompas, 2010) ; Joko Suryo (livre de Iwan Nurdaya-Jafar, sur le voyage de Tagore à Java et Bali en 1927) ; Mona Lohanda (livre de A. Heuken, Paintings and Description of Batavia in Heydt's book of 1744, Jakarta, 2013) ; S. Margana (Tomé Pires, traduction indonésienne de la Suma Oriental, 2014); Halim HD (Gunung Kidulan oleh wonggunung, énorme ouvrage en indonésien et javanais, non commercialisé, sur la culture de cette région de Java Centre) ; Andi Muhammad Akhmar (Islamisasi Bugis, thèse publiée en 2018 sur l'épopée La Galigo) ; Azhari Aiyub (son roman Kura-Kura Berjanggut, 2018) ; I Gusti Dibal Ranuh (livre sur le voyage du sage Dang Hyang Nirata, au XVI ${ }^{\mathrm{e}}$ s., à Bali).

Un buffet était servi dans la même salle, tandis qu'un orchestre des Îles de la Sonde jouait devant l'estrade. La soirée s'est terminée sur une conférence extrêmement technique de Hudaja Kandahjaya sur « Le Borobudur, représentation d'un cheminement spirituel en trois dimensions ». Durant toute la soirée, des stands, dans les couloirs, proposaient des publications de 28 éditeurs.

Tous les participants ont quitté Yogyakarta le soir même, afin de s'installer dans plusieurs petits hôtels situés dans les environs du Borobudur. C'est à l'intérieur du parc du Borobudur que se tinrent les manifestations des deux jours suivants ( 23 et 24 novembre), très nombreuses et réparties sur plusieurs lieux, de sorte qu'il était impossible d'assister à toutes. Le lieu principal était un espace comprenant plusieurs bâtiments ; une cour centrale, où avaient lieu les repas, était en permanence un espace de rencontres et de discussions informelles.

L'activité centrale était un symposium consacré, conformément au thème de l'année, aux récits laissés par les voyageurs étrangers en Indonésie et divisé en quatre sessions de quatre communications chacune : 
1. Voyageurs chinois en Insulinde

- Voyages chinois à l'époque de Majapahit, Nurni W. Wuryandari

- Rapports des voyageurs chinois à Malacca et en Insulinde, Tan Ta Sen

- Les notes de voyage de I-Tsing en Insulinde, Shinta Lee

- Voyages bouddhistes à Sumatra et à Java, Bambang Budi Utomo

2. Voyageurs musulmans en Insulinde

- Les réseaux musulmans en Insulinde, Azyumardi Azra

- Le récit de voyage de Ibn Battutah, Taufik Abdullah

- Les récits des pèlerins indonésiens à La Mecque, Henri Chambert-Loir

- Les chroniques du Sam Pho Kong en rapport avec les Wali Sanga, Widyo Nugrohanto

3. Voyageurs indiens en Insulinde

- Le voyage d'Atisha en Insulinde, Suhu Bhadra Ruci

- Les récits par Rabindranath Tagore de son voyage à Java et Bali, Sugi Lanus

- Le livre de V.S. Naipaul sur l'Indonésie, Among the Believers, Ulil Absar Abdullah

- L'influence de la théosophie sur les oeuvres de Cipto Mangunkusumo et Ki Hajar Dewantoro, Iskandar P. Nugraha

4. Voyageurs européens en Insulinde

- Les récits de voyages et les rapports européens, dont celui de Tomé Pires, comme documents historiques, Djoko Marihandono

- L'Herbariusm Amboinense (1741) de G.E. Rumphius, C.J. Bohm

- The Malay Archipelago d'Alfred Russel Wallace (1869), Sangkot Marzuki

Parallèlement, avaient lieu un grand nombre d'activités :

- Séances de méditation deux fois par jour : l'une à 5 heures du matin, devant le Borobudur, animée par Romo Sudrijanta SJ et Yudhi Widdyantoro (professeur de yoga), la deuxième en fin d'après-midi, sur le lieu du colloque, animée par Laura Romano (adepte de l'école de kejawen Sumarah).

- Causeries de quatre lauréats des résidences d'écrivains à l'étranger attribuées annuellement, depuis 2016, par le Komite Buku Nasional du ministère de la Culture : Martin Aleida, Agustinus Wibowo, Cok Sawitri, Faisal Oddang.

- Conférence de Peter Carey sur le destin archéologique du site de la capitale de Majapahit, à Trowulan, soit la politique de négligence plus ou moins délibérée des régimes anglais (Raffles), néerlandais et indonésien, jusqu'à aujourd'hui.

- Un atelier consacré aux contes pour enfants, destiné aux enfants des 
villages environnants, avec des contes choisis en fonction des récits sculptés sur les bas-reliefs du Borobudur.

- Projection, au Pesantren Pabelan, de trois films de fiction sur le thème Islam et tolérance : 3 Doa 3 Cinta, Bid'ah Cinta et Khalifah, suivie de discussions avec les santris.

- Stands de livres de 40 éditeurs de Jakarta, Bandung et Yogyakarta.

- Lecture des reliefs du Borobudur : conférence de Salim Lee, qui dirigeait également, le lendemain, une viste des galeries du monument.

Six spectacles artistiques (trois chaque soir) mêlant installations, théâtre et danse, sur le thème de migrations physiques et spirituelles, sur la scène du Panggung Aksobhya, situé au sud-est du Borobudur, avec le temple en arrièreplan :

1. Melati Suryodarmo \& Katsura San, Luminous Emptiness. Le voyage des âmes, à travers chorégraphie et musique japonaise et javanaise, et inspiré du Livre des morts tibétain.

2. Ery Mefri, Sangketohawa.

3. Cok Sawitri, Sakyamuni Itu Saja (Perlu Mati).

4. Tony Broer et Katia Engel, Batu Bergerak. Voyage des pierres qui ont servi à construire les trois temples de Borobudur, Pawon et Mendut.

5. Anwari, Menjahit kertas. Célébration de la vie quotidienne madouraise.

6. Yusil Katil, Under the Volcano. Inspiré du Syair Lampung Karam, de la présence du Marapi et de la structure sociale Minangkabau.

Le magazine Tempo du 3 décembre 2018 contient cinq pages sur ces spectacles.

- La pièce d'Arifin C. Noer Orkes Madun jouée par le groupe Wayang Cing Cing Mong avec des marionnettes en ronde-bosse (golek).

- Un prix est attribué chaque année à un acteur culturel pour récompenser son activité dans le cadre du thème annuel. Ce prix, nommé Sang Hyang Kamahayanikan Award, a été attribué, entre 2012 et 2017, à S.H. Mintardja, A.B. Lapian, Peter Carey, Nigel Bullough, Halilintar Latief \& Kartono Kamajaya (ob.) et Noerhadi Magetsari. Le lauréat de 2018 est le professeur malaysien Tan Ta Sen.

$\mathrm{Au}$ total, un événement mis en scène avec une rigueur impeccable, orchestré et maîtrisé avec le plus parfait professionalisme par une équipe dirigée par Yessi Apriati. Le public était constamment nombreux, en dépit du lieu relativement retiré.

L'atmosphère était palpitante d'activité intellectuelle et artistique, avec une ouverture d'esprit constamment affirmée, à l'encontre des carcans conventionnels de la pensée officielle. Le choix du lieu, les nombreuses références au Borobudur et au bouddhisme, la présence de moines bouddhistes dans l'auditoire et parmi les conférenciers, la place de choix faite aux Chinois dans l'histoire de l'archipel et dans l'histoire de l'islam local, les séances 
de méditation, l'inspiration d'une partie des spectacles, le rôle de plusieurs prêtres, bien des éléments de ces journées culturelles intenses reflétaient un aspect de la culture indonésienne moderne, ouverte à son propre passé et au monde, très éloignée des pesanteurs que les institutions imposent à la définition de la culture nationale. L'Indonésie célèbre perpétuellement sa « diversité » ethnique et culturelle inscrite dans la devise nationale (Bhineka Tunggal Ika). Le Festival proposait le concept de pluralisme, soit la diversité conçue comme une idéologie culturelle, avec pour maître mot l'œcuménisme.

HENRI CHAMBERT-LOIR 